\title{
REATOR DE MEMBRANA ENZIMÁTICO E FLUIDOS SUPERCRÍTICOS: ASSOCIAÇÃO DE PROCESSOS
}

Juliana Maria Leite Nóbrega de Moura*, Ana Paula Badan Ribeiro, Renato Grimaldi e Lireny Aparecida Guaraldo Gonçalves Departamento de Tecnologia de Alimentos, Faculdade de Engenharia de Alimentos, Universidade Estadual de Campinas, CP 6091, 13081-970 Campinas - SP, Brasil

Recebido em 3/7/06; aceito em 28/9/06; publicado na web em 28/5/07

ENZYMATIC MEMBRANE REACTOR AND SUPERCRITICAL FLUIDS: PROCESS ASSOCIATION. The aim of this work is to present the new applications of membrane technology in fat and oil processing, with emphasis on development and applications of the enzymatic membrane reactor and its association with extraction and purification technology by supercritical fluids (SCF). Combining the extraction by SCFs and the separation by membranes allows the integration of extractions reactions with selective separation by membranes through filtration of the supercritical mixture ( $\mathrm{SCF}+$ extracted solutes). This association provides important energy savings regarding the SCF recompression costs.

Keywords: membrane reactor; supercritical fluids; enzymatic reactor.

\section{INTRODUÇÃO}

A tecnologia de membranas tem se desenvolvido bastante nas últimas décadas e suas aplicações têm se expandido em vários setores industriais: químico, petroquímico, mineral e metalúrgico, farmacêutico, alimentício, tratamento de águas residuais etc. A separação por membranas compete com métodos físicos de separação, como a adsorção seletiva, absorção, extração por solventes, destilação, cristalização e outras técnicas. A diferença entre o processo de separação por membranas e outras técnicas de separação é a provisão da fase da membrana, que é geralmente definida como uma barreira seletiva entre duas fases e normalmente se refere a membranas sintéticas ${ }^{1}$.

O processo de separação por membranas é, principalmente, um processo regido sob pressão, baseado na exclusão dos componentes de acordo com suas massas molares, formas específicas e nas interações entre os componentes e a superfície da membrana ${ }^{2}$. Quando esta barreira imperfeita é colocada entre duas fases, a existência de uma força motriz propicia o fluxo de solvente e/ou soluto. Esta força motriz pode estar associada à diferença de concentração, pressão, potencial elétrico e temperatura. Nas operações governadas por diferenciais de pressão, tais como filtração clássica (FC), microfiltração (MF) e ultrafiltração (UF), a separação das partículas e macromoléculas ocorre em função de suas dimensões ou massas molares médias. Já na nanofiltração (NF) e osmose reversa (OR), pequenas moléculas são separadas também em função de um mecanismo de solução-difusão no material da membrana. Entretanto, em todos os casos, ocorrem sempre interações entre o material da membrana e o soluto ${ }^{3}$.

O desempenho de separação das membranas é afetado pela sua composição, temperatura, pressão, vazão de alimentação e interações entre os componentes da solução e a superfície da membrana ${ }^{4}$. Suas principais características estão relacionadas ao perfil de tamanho dos poros (usualmente o diâmetro dos poros ou equivalente), densidade dos poros (número de poros por unidade de área de superfície da membrana) e porosidade, que é a fração de volume não ocupado pela própria membrana. Outras características importantes são a rejeição da membrana em relação a determinados solutos, os fluxos de permeado, a resistência a temperaturas elevadas e, solventes e pressões utilizadas ${ }^{2}$.

*e-mail: jumanobrega@yahoo.com.br
As membranas industriais podem ser classificadas em várias categorias com base na pressão a ser utilizada e na massa molar dos solutos a serem separados. A microfiltração utiliza pressões inferiores a 0,2 MPa e separa moléculas entre 0,025-10 $\mu \mathrm{m}$; a ultrafiltração utiliza pressões acima de 1,0 MPa e geralmente separa partículas de peso molecular entre 1 e $300 \mathrm{KDa}$; a nanofiltração utiliza pressões entre 1 e 4 MPa e separa partículas de massa molar entre 350 e 1000 Da e a osmose reversa utiliza pressões entre 4 e $10 \mathrm{MPa}$ e concentra partículas com massa molar de corte menor que $350 \mathrm{Da}^{5}$.

$\mathrm{O}$ interesse na aplicação de membranas em tecnologias de lipídios tem crescido bastante nos últimos anos. As aplicações geralmente melhoram o processo de produção, simplificando-o, reduzindo o consumo de energia e a produção de águas residuais, com a possibilidade de não adição de insumos químicos e de fácil mudança de escala ${ }^{5}$.

A maioria das pesquisas utilizando membranas em tecnologia de lipídios tem focado a recuperação de solvente da miscela de extração, a degomagem, o branqueamento, a neutralização, a hidrólise de óleos e gorduras, a síntese enzimática, a extração e a purificação de matrizes lipídicas através da utilização de reatores de membranas e fluidos supercríticos ${ }^{6-10}$.

\section{BIOCONVERSÃO ENZIMÁTICA}

As propriedades físico-químicas, nutricionais e o valor comercial de óleos e gorduras dependem de sua estrutura triacilglicerólica, relacionada aos ácidos graxos presentes e suas respectivas posições na molécula de glicerol. A modificação destas matérias-primas tem sido extensivamente realizada por processos como fracionamento, hidrogenação e interesterificação, visando a melhoria de suas propriedades funcionais. Entretanto, a crescente disponibilidade comercial de enzimas relacionadas à tecnologia de lipídios tem promovido alternativas interessantes aos processos de modificação usualmente empregados pela indústria de óleos vegetais ${ }^{11}$.

As enzimas apresentam diversas vantagens quando utilizadas em processos industriais. As reações enzimáticas podem ocorrer sob condições brandas de temperatura, $\mathrm{pH}$ e pressão, exigindo menor consumo energético e minimizando a degradação térmica dos produtos finais. Em função da seletividade enzimática é possível a obtenção de produtos específicos, que dificilmente seriam obtidos por reações 
químicas convencionais. As lipases podem catalisar reações de hidrólise, esterificação, alcoólise, acidólise e transesterificação ${ }^{12}$.

Os processos de bioconversão enzimática têm sido bastante utilizados na produção, transformação e valorização de matériasprimas. Importantes aplicações têm sido realizadas nas indústrias alimentícias, farmacêuticas e no desenvolvimento de propostas ambientais. A maioria das reações enzimáticas é realizada em reatores por bateladas, apresentando alguns inconvenientes como altos custos operacionais, baixa produtividade, alta variação na qualidade dos produtos obtidos e problemas de remoção da enzima ${ }^{13}$.

Visando a obtenção de reações com maior uniformidade tecnológica e viabilidade econômica, a utilização de enzimas na forma imobilizada permite considerável aumento na estabilidade e maior diversidade de aplicação, de fundamental importância para o desenvolvimento de processos associados à bioconversão ${ }^{14}$. A utilização de enzimas imobilizadas confere maior produtividade, facilidade na automação de processos e operações contínuas, controle preciso da extensão das reações, facilidade de separação dos produtos obtidos, estabilização da atividade enzimática, facilidade de recuperação e reutilização das enzimas ${ }^{15}$.

\section{REATOR DE MEMBRANA}

O conceito básico de reator de membrana é baseado na separação da enzima e produtos (ou substratos) por uma membrana seletiva que cria uma barreira entre as fases. Solutos permeáveis podem ser separados da mistura de reação por uma força propulsora (potencial químico, pressão, campo elétrico etc.) que atue através da membrana. A separação dos reagentes dos produtos, bem como a recuperação e o reuso de catalisadores da mistura reacional, constitui-se em uma etapa de grande importância econômica do processo. Reatores de membranas visam integrar a conversão catalítica, separação de produtos e/ou concentração e recuperação de catalisador em uma única etapa. As membranas também podem ser utilizadas em reator exclusivamente como matrizes para imobilização da enzima, sem nenhuma intenção de separação ${ }^{16}$.

As membranas de ultrafiltração, devido sua ampla faixa de distribuição de poros (entre 1-100 nm ou massa molar de corte - MMC 500-100.000 Da), são mais adequadas para retenção da maioria das enzimas (10.000-100.000), nativas ou modificadas. A massa molar de corte de uma membrana é dada pela massa molar da menor molécula retida em pelo menos $90 \%$ pela membrana ${ }^{16,17}$.

A seleção da membrana a ser utilizada em reatores de membranas enzimáticos deve levar em consideração o tamanho da enzima, substratos e produtos, bem como a natureza química das substâncias e do material da membrana. Um importante parâmetro a ser utilizado nesta seleção é o coeficiente de rejeição de solutos, que deve ser zero para facilitar a permeação, e deve ser $100 \%$ para a enzima, permitindo completa retenção do catalisador no sistema reacional ${ }^{16}$.

Em função do tipo de contato entre enzimas e substratos, os reatores de membranas podem ser classificados em: reator de membrana com contato direto - ocorre o contato direto entre enzimas e substratos (i.e., substratos são introduzidos no lado da membrana que contém a enzima). Neste tipo de reator as enzimas (imobilizadas ou em sua forma livre) podem atuar no substrato tão logo entrem no sistema; reator de membrana por difusão - promove o contato entre enzima e substrato após a passagem difusiva dos substratos através da membrana para o compartimento adjacente onde a enzima está localizada, solúvel ou imobilizada. Após a catálise os produtos difundem-se no sentido do fluxo de substratos que ainda não reagiram; reator de membrana multifásico - a membrana não apenas separa duas fases de líquidos mas também promove um contato interfacial, juntamente com a enzima, atuando como um catalisador ${ }^{16}$.
Um reator combinando enzima, membrana e $\mathrm{CO}_{2} \mathrm{SC}$, foi utilizado por Pomier et al. ${ }^{18}$ para modificação de óleo de mamona. $\mathrm{O}$ reator baseia-se em dois conceitos originais: fluidificação da mistura viscosa (óleo de mamona e oleato de metila) pelo $\mathrm{CO}_{2} \mathrm{SC}$, facilitando a filtração tangencial e reação enzimática em meio $\mathrm{CO}_{2} \mathrm{SC} /$ óleo, catalisada por lipase imobilizada em suporte cerâmico $^{19}$. Através da análise de retentados e permeados, quanto à presença de ricinoleato de metila, verificou-se que a reação enzimática aconteceu predominantemente nos poros da membrana, onde o contato entre enzimas e substratos é favorecido em relação à superfície interna da membrana. Durante $25 \mathrm{~h}$, a atividade de conversão da enzima imobilizada foi de aproximadamente $30 \%$ no permeado e $16 \%$ no retentado.

$\mathrm{Xu}$ et al. ${ }^{20}$ investigaram a utilização de reator de membrana na síntese enzimática de lipídios estruturados buscando obter a integração da reação de interesterificação e de separação dos lipídios estruturados específicos, visto que os processos acontecem simultaneamente, permitindo assim uma forma de otimização. Especificamente, a integração de reações catalisadas enzimaticamente com a tecnologia de separação por membranas constitui uma melhoria em potencial em alguns processos. A separação simultânea de substratos indesejáveis pode alterar a concentração durante o processo de reação, conduzindo a reação para um melhor nível de equilíbrio. Os autores avaliaram 26 membranas planas de distintos materiais poliméricos. As membranas foram selecionadas em termos de suas habilidades de separar os ácidos graxos de cadeia média (AGCM) liberados dos TG de cadeia média (TGCM), sob processo de acidólise com concentrado de ácidos graxos poliinsaturados de óleo de peixe, e menor taxa de permeação de óleo de canola, que atuou como óleo extrator. Foram também avaliados a estabilidade das membranas e o efeito do comprimento da cadeia dos ácidos graxos nos fluxos de efluentes. As reações foram realizadas em reator de membrana baseado no processo de difusão. Utilizou-se a enzima Lipozyme IM $s n-1,3$ específica como biocatalisador. A incorporação de ácidos graxos poliinsaturados n-3 (PUFA) foi aumentada em $15 \%$, em 90 h de reação, através da separação simultânea dos AGCM liberados pela reação.

$\mathrm{Xu}$ et al. ${ }^{9}$ investigaram a obtenção enzimática de lipídios estruturados específicos através da utilização de reator de membrana de ultrafiltração. A reação de interesterificação enzimática ocorreu entre TCM e ácidos graxos poliinsaturados de cadeia longa de óleo de peixe, com razão molar de 1:4, respectivamente. Utilizou-se como catalisador a enzima Lipozyme TL IM, $s n-1,3$ específica $(5 \% \mathrm{p} / \mathrm{p})$, com umidade de $3 \%$. Os experimentos foram realizados em célula de ultrafiltração, sob atmosfera de nitrogênio, temperatura de $50{ }^{\circ} \mathrm{C}$ e agitação de 200-400 rpm. Após $5 \mathrm{~h}$ de reação, aplicou-se pressão transmembrana de 1 bar. A incorporação de ácidos graxos poliinsaturados nos TCM aumentou cerca de $15 \%$, após $80 \mathrm{~h}$ de experimento, através da separação simultânea dos AGCM liberados pela reação.

\section{IMOBILIZAÇÃO ENZIMÁTICA}

Diversos sistemas têm sido propostos para imobilização enzimática: adsorção ou ligação covalente de moléculas catalisadoras em suporte sólido, reticulação ou inclusão em cápsula, matriz ou fibra. A escolha da técnica a ser utilizada tem sido determinada principalmente pelo tempo, em detrimento do tipo e escala da aplicação considerada. Reduções na atividade enzimática de 10 a $90 \%$ têm sido relatadas na literatura. Várias razões podem estar envolvidas na explicação destes fenômenos, incluindo o impedimento estérico (o sítio ativo da enzima pode ter sido alterado pelo processo de imobilização) ou o fenômeno de limitação interfacial (a difusão dos 
substratos ou produtos nas imediações da superfície onde as moléculas catalisadoras são imobilizadas pode ser muito lenta) ${ }^{13}$.

Rucka e Turkiewicz ${ }^{21}$ avaliaram técnicas de impregnação enzimática (Rhizopus sp.) por oclusão da enzima na matriz polimérica e adsorção em membranas de ultrafiltração. A imobilização na membrana, durante seu processo de elaboração, mostrouse como uma alternativa simples e atrativa em relação à imobilização por adsorção. A oclusão física da enzima pela matriz polimérica é mais forte que a adsorção, onde interações hidrofóbicas não são fortes o suficiente para manutenção da lipase ligada a membrana. O principal benefício associado à imobilização da enzima por oclusão durante o processo de inversão de fases é a obtenção de uma membrana com bom tempo de estabilidade.

Bouwer et al. ${ }^{22}$ avaliaram o desempenho de reatores de membrana com lipase Rhizopus javanicus imobilizada através da filtração de solução enzimática. Para aplicação em reatores, lipases têm sido imobilizadas em membranas microporosas hidrofóbicas e hidrofílicas. As membranas têm aproximadamente a mesma produtividade, mas a atividade enzimática é muito menor com membranas hidrofóbicas. O fator limitante mais importante é a baixa utilização da enzima devido à zona de contato entre as fases aquosa e orgânica nas membranas hidrofóbicas ser muito fina, permitindo a atuação da lipase somente nessa zona de contato. Para aplicações economicamente viáveis, membranas hidrofílicas são preferidas desde que menor quantidade de enzima seja requerida. Foram testadas membranas tipo fibra oca (com 40 canais de 1,8 $\mathrm{mm}$ d.i., espessura da parede $0,065 \mathrm{~mm}$, área porosa interna $680 \mathrm{~m}^{2}$ ) e membranas planas (espessura de $120 \mu \mathrm{m}$, área de superfície $0,029 \mathrm{~m}^{2}$ e área porosa interna de $53 \mathrm{~m}^{2}$ ). As reações estudadas foram a hidrólise de TG e a peroxidação de ácidos graxos. No caso da hidrólise, as atividades das membranas foram da mesma magnitude $\left(\sim 20 \mu \mathrm{mol} \mathrm{m} \mathrm{m}^{-2} \mathrm{~s}^{-1}\right)$ independentemente do tipo de membrana ou de sua espessura. $\mathrm{O}$ modelo de reação-difusão foi desenvolvido para que se conseguissem duas zonas na membrana, uma camada de difusão e uma camada de reação. Com este modelo, a espessura da camada de reação e o grau de utilização da enzima podem ser estimados.

Balcão e Malcata ${ }^{23}$ relataram mudanças ocorridas na composição em ácidos graxos da manteiga submetida à acidólise com ácido oléico através da utilização da lipase comercial Mucor javanicus, imobilizada por adsorção física em membrana fibra oca hidrofóbica, a $40{ }^{\circ} \mathrm{C}$ e sob atividade de água controlada. O principal objetivo dessa pesquisa foi aumentar o nível de ácidos graxos insaturados da manteiga e reduzir, concomitantemente, o nível de ácidos graxos saturados de cadeia média e longa (láurico e mirístico). Com a hidrólise, observou-se na manteiga modificada um aumento de $30 \%$ p/p de ácido oléico e redução de 8 e $2 \%$ para os ácidos graxos láurico e mirístico, tendo em vista a composição original da manteiga. A imobilização da enzima na membrana foi por adsorção, seguindo procedimentos descritos por Balcão, Vieira e Malcata (1996) e Balcão e Malcata (1997). O conteúdo de pó da lipase bruta (M10 ${ }^{\mathrm{TM}}$ ) foi aproximadamente $10 \%$ (peso/peso). A quantidade de proteína adsorvida pela membrana de fibra oca foi de 6,36 ug proteína $/ \mathrm{cm}^{2} \mathrm{de}$ membrana e correspondeu a um rendimento de imobilização de aproximadamente $54 \%$ de proteína da solução sobrenadante.

Lozano et al. ${ }^{24}$ otimizaram o método de preparo de membranas dinâmicas através da filtração de solução de polímeros solúveis em água (gelatina e/ou polietilenoimina - PEI) em suporte cerâmico $\alpha$-alumina, seguido da imobilizacão da enzima Candida antartica B (CALB) através de ligação covalente. A enzima liga-se covalentemente à camada de gelatina e/ou PEI previamente adsorvida utilizando-se glutaraldeído como agente ligante. O processo de imobilização da CALB em membranas dinâmicas foi otimizado em função dos diferentes parâmetros envolvidos em cada etapa (formação da camada dinâmica, ativação com glutaraldeído e ligação enzimática) tendo como critérios de avaliação a atividade hidrolítica do p-nitrofenil palmitato e a estabilidade operacional. A membrana preparada com deposição de gelatina/PEI foi utilizada na obtenção de butirato de butila a partir de butirato de vinila e 1-butanol com três solventes orgânicos (hexano, acetona e acetonitrila) e em meio com baixo teor de umidade ( $<3 \% \mathrm{v} / \mathrm{v})$. A "membrana enzimática" apresentou maior estabilidade operacional em meio anidro, possivelmente atribuída à não solubilização da camada de gel (gelatina/PEI e de moléculas de enzimas).

Magnan et al. ${ }^{19}$, através de adaptação do protocolo de imobilização descrito por Lozano et ll $^{24}$, avaliaram a estabilidade e atividade de membrana cerâmica imobilizada com Candida antartica quanto à reação de hidrólise de acetato butílico em água e síntese de laurato butílico a partir de acetato butílico e ácido láurico em solventes orgânicos. Verificou-se boa reprodutibilidade na elaboração das membranas, através do controle de determinações hidrolíticas, e boa estabilidade da membrana enzimática à estocagem a temperatura ambiente, sob vácuo com $\mathrm{P}_{2} \mathrm{O}_{5}$. A estabilidade enzimática da membrana foi avaliada após quatro reutilizações, onde a membrana, depois de utilizada, foi lavada, seca e acondicionada até a próxima utilização. Após redução de $35 \%$ na atividade hidrolítica entre a primeira e segunda utilização, a atividade permaneceu constante. Como a estocagem não ocasionou perda na atividade enzimática, a redução observada pode ser associada às etapas de secagem e hidratação das membranas. Segundo os autores, o processo de secagem induz a remoção da água da estrutura da camada de gel polimérica, sendo responsável pela aproximação das cadeias protéicas. Estas interações podem ocasionar modificações irreversíveis na conformação da estrutura enzimática, favorecendo sua inativação. Contudo, como parte das enzimas está ligada covalentemente por mais de uma ligação, suas estruturas são fixas e modificações na sua conformação, envolvendo sua inativação, não podem mais ocorrer durante a secagem, o que torna desprezível a perda de atividade após dois ciclos de estocagem.

\section{FLUIDOS SUPERCRÍTICOS}

Fluidos supercríticos são substâncias que se encontram sob condições críticas de pressão e temperatura, ou seja, acima de sua pressão e temperatura críticas ${ }^{25}$. No estado supercrítico, as propriedades físico-químicas de um fluido assumem valores intermediários àqueles dos estados líquido e gasoso, apresentando densidade próxima à dos líquidos, viscosidade próxima à dos gases, difusividade duas vezes maior que a típica dos líquidos, alta compressibilidade e baixa tensão superficial ${ }^{25,26}$.

Fluidos supercríticos (FSC) têm recebido bastante atenção no que se refere aos processos de extração, apresentando diversas vantagens em relação ao processo de extração com solventes orgânicos. Entre estas vantagens, citam-se a baixa viscosidade e alta difusividade dos FSC, melhorando a transferência de massa em matrizes sólidas e líquidas, com redução do tempo total de extração; possibilidade de utilização sob temperaturas brandas, conferindo maior proteção oxidativa aos compostos termo-sensíveis; possibilidade de modificação de suas propriedades de solvatação através do ajuste da pressão e temperatura, permitindo a obtenção de extrações seletivas; fácil remoção do produto extraído através de sua descompressão; são considerados seguros para o meio ambiente e não geram resíduos químicos ${ }^{27}$.

Em particular, o dióxido de carbono $\left(\mathrm{CO}_{2}\right)$ é o FSC mais utilizado como solvente em aplicações alimentícias. $\mathrm{O} \mathrm{CO}_{2}$ apresenta baixo custo, disponibilidade em alto grau de pureza, facilidade e segurança em sua manipulação, é atóxico, não inflamável, apresentando interessantes propriedades físico-químicas, como baixo ponto crítico de temperatura e pressão, $31,1{ }^{\circ} \mathrm{C}$ e 72 bar, respectivamente $e^{25,28}$. 
A aplicação da tecnologia de fluidos supercríticos (FSC) no processamento de óleos e gorduras é uma alternativa aos processos de extração e purificação de matrizes lipídicas envolvendo solventes orgânicos. A extração e purificação de compostos lipídicos, como triacilgliceróis, ácidos graxos livres, tocoferóis, carotenóides, esteróis, através do $\mathrm{CO}_{2} \mathrm{SC}$ tem sido investigada por diversos autores, bem como a influência dos parâmetros operacionais utilizados, temperatura e pressão de $\mathrm{CO}_{2}$, sobre a seletividade da extração $26,27,29-33$.

\section{ASSOCIAÇÃO DE EXTRAÇÃO POR FSC E TECNOLOGIA DE MEMBRANAS}

A associação do processo de extração por FSC e separação por membranas permite a integração da reação de extração pelo $\mathrm{CO}_{2} \mathrm{SC}$ (favorecida pelo seu alto poder solvente) e separação seletiva pela membrana, através da filtração da mistura supercrítica $\left(\mathrm{CO}_{2} \mathrm{SC}+\right.$ solutos extraídos). A combinação do sistema $\mathrm{CO}_{2} \mathrm{SC} / m e m b r a n a$ confere melhoria no potencial de separação da membrana e seletividade para a extração, possibilitando a extração de frações com estreita faixa de massa molar ${ }^{34}$.

A separação de solutos no processo de extração por FSC realiza-se através de despressurização e/ou resfriamento, onde o fluido passa à forma gasosa, seguido da coleta dos solutos extraídos. Os custos de recompressão do $\mathrm{CO}_{2}$ gasoso para a fase líquida ou supercrítica são altos e a associação do processo de extração por FSC e separação por membranas permite a não expansão do fluxo do retentado a cada ciclo, permitindo uma importante economia energética quanto aos custos de recompressão $0^{34,35}$.

Sarrade et al. ${ }^{34}$ utilizaram a associação da extração de $\mathrm{CO}_{2} \mathrm{SC}$ e separação através de membranas de nanofiltração no fracionamento de triacilgliceróis de óleo de peixe e na purificação de B-caroteno. Foram testadas duas membranas tubulares: $\mathrm{TN}$ - baseada no conceito orgânico-inorgânico e T - baseada no conceito inorgânico. A referida associação permitiu o fracionamento de triacilgliceróis de óleo de peixe, determinado através da verificação do aumento de triacilgliceróis de cadeia média no permeado e predominância de triacilgliceróis de cadeia longa no retentado. A membrana TN apresentou maior seletividade quanto ao fracionamento de triacilgliceróis que a membrana T. Foram utilizadas condições operacionais de $31 \mathrm{MPa}, 313 \mathrm{~K}$, pressão transmembrana de $3 \mathrm{MPa}$. Para a purificação de carotenóides, provenientes do óleo de cenoura, obteve-se um aumento de $30 \%$ de caroteno no retentado através da utilização da membrana TN. A membrana T não foi efetiva na retenção de carotenos.

Spricigo et al. ${ }^{35}$ testaram uma membrana de osmose reversa de acetato de celulose quanto à separação de óleo essencial de nozmoscada na presença de $\mathrm{CO}_{2} \mathrm{SC}$. A membrana apresentou uma retenção média de óleo essencial de $96,4 \%$, não tendo sido influenciada de forma significativa pela temperatura, pressão transmembrana e concentração de óleo na alimentação. Para pressão de $\mathrm{CO}_{2}$ de 12 $\mathrm{MPa}$, maiores fluxos de permeado foram obtidos com pressão transmembrana de $4 \mathrm{MPa}$, sem perdas na retenção do óleo essencial. $\mathrm{O}$ fluxo de $\mathrm{CO}_{2}$ foi linearmente proporcional à pressão transmembrana aplicada, sendo reduzido com o aumento da concentração de óleo na alimentação. A membrana apresentou boa permeabilidade ao $\mathrm{CO}_{2} \mathrm{e}$ boa resistência às severas condições de pressão utilizadas.

Sarmento et al. $^{36}$ avaliaram três membranas de osmose reversa ( $\mathrm{SG}, \mathrm{CG}$ e AG - Osmonics) quanto à permeabilidade ao $\mathrm{CO}_{2} \mathrm{SC}$ e retenção de limoneno e óleos essenciais de noz-moscada e laranja a $12 \mathrm{MPa}$ e $40{ }^{\circ} \mathrm{C}$. A retenção de óleos e a permeabilidade ao $\mathrm{CO}_{2} \mathrm{SC}$ foram avaliadas em função da concentração na alimentação e pressão transmembrana. O fluxo de $\mathrm{CO}_{2}$ foi linearmente dependente da pressão transmembrana aplicada. A retenção de óleos essenciais foi reduzida com o aumento da pressão transmembrana, não sendo afe- tada pelas diferentes concentrações de óleo na alimentação. A membrana SG apresentou maior retenção de óleos essenciais, atingindo valores de aproximadamente $90 \%$. No entanto, concomitantemente, esta membrana apresentou menor fluxo de $\mathrm{CO}_{2}$, com valores de até $8,75 \mathrm{~kg} / \mathrm{h} \mathrm{m}^{2}$, quando submetida à diferença de pressões de $1 \mathrm{MPa}$. Os resultados experimentais indicaram a ocorrência de colmatagem da membrana após a permeação de óleo essencial. Todas as membranas testadas apresentaram boa permeabilidade ao $\mathrm{CO}_{2}$ e boa resistência às severas condições de pressão utilizadas.

Carlson et al..$^{10}$ avaliaram três membranas de osmose reversa (SG, AK e CE - Osmonics) e uma de nanofiltração (HL - Osmonics) quanto à retenção de D-limoneno sob extração por $\mathrm{CO}_{2} \mathrm{SC}$. Os experimentos foram conduzidos sob pressão de $12 \mathrm{MPa}$, pressão transmembrana de $0,5 \mathrm{MPa}$ e temperatura de $40{ }^{\circ} \mathrm{C}$. A membrana SG apresentou maior fator de retenção de D-limoneno $(0,94)$ para concentração de limoneno na alimentação de 30\%; apresentando, no entanto, baixos fluxos de $\mathrm{CO}_{2}$. Os resultados obtidos com a membrana SG mostraram que a associação de membranas e extração com $\mathrm{CO}_{2} \mathrm{SC}$ representa aplicação potencial para a redução de custos energéticos na reciclagem do solvente. Com esta membrana, quase $70 \%$ do solvente (permeado de $\mathrm{CO}_{2}$ ) pôde ser reciclado com apenas $0,5 \mathrm{MPa}$ de pressurização (de 11,5 a 12,0 MPa) enquanto que para os $30 \%$ restantes (retentado $\mathrm{CO}_{2}$ ) houve necessidade de pressurização de 5 a $12 \mathrm{MPa}$, para a ocorrência de mudança de fase, com maior necessidade de energia para se atingir a pressão de extração. A membrana $\mathrm{CE}$ apresentou fluxo de $\mathrm{CO}_{2}$ praticamente nulo, inviabilizando testes com a matriz lipídica. $\mathrm{O}$ fator de retenção da membrana $\mathrm{AK}$ foi reduzido a zero após 80 min de filtração. A membrana HL apresentou fator de retenção estável $(0,3)$ após 75 min.

\section{CONCLUSÃO}

A utilização de reatores de membrana enzimáticos constitui-se em uma tecnologia promissora para os processos de bioconversão devido à possibilidade de ocorrência simultânea da reação enzimática, separação entre enzima e produtos/substratos e separação e/ou purificação de produtos, em função da disposição da enzima no reator de membrana, em sua forma livre ou imobilizada. Reações enzimáticas conduzidas em meio de $\mathrm{CO}_{2} \mathrm{SC}$ são favorecidas pelo alto poder solvente do $\mathrm{CO}_{2}$, podendo favorecer a atividade catalítica. A associação do processo de extração por FSC e separação por membranas constitui-se em uma ferramenta de grande impacto econômico e ambiental, podendo ser considerada como uma tecnologia limpa e segura quando comparada aos processos que envolvem extração e purificação com solventes orgânicos.

\section{REFERÊNCIAS}

1. Mulder, M.; Basic Principles of Membrane Technology, $5^{\text {th }}$ ed., Kluwer Academic Publishers: Dordrecht, 1996.

2. Cheryan, M.; Ultrafiltration and Microfiltration Handbook, Technomic Publ. Co.: Ilinois, 1998.

3. Frieldlander, H. Z.; Rickes, R. N.; Chem. Eng. 1996, 73, 111.

4. Lin, L.; Rhee, K. C.; Koseoglu, S. S.; J. Membr. Sci. 1997, 134, 101.

5. Snape, J. B.; Nakajima, M.; J. Food Eng. 1996, 30, 1.

6. Moura, J. M. L. N.; Gonçalves, L. A. G.; Petrus, J. C. C.; Viotto, L. A.; J. Food Eng. 2005, 70, 473.

7. Ribeiro, A. P. B.; Soares, M. S. S.; Moura, J. M. L. N.; Cáceres, M. C.; Gonçalves, L. A. G.; Boletim CEPPA 2005, 23, 1.

8. Saravan, M.; Bhosle, B. M.; Subramanian, R.; J. Food Eng. 2006, 74, 529.

9. Xu, X.; Skands, A.; Jonsson, G.; Adler-Nissen, J.; Biotechnol. Lett. 2000, 22, 1667.

10. Carlson, L. H. C.; Bolzan, A.; Machado, R. A. F.; J. Supercrit. Fluids 2005 , 34, 143.

11. Pugazhenti, G.; Kumar, A.; J. Membr. Sci. 2004, 228, 187.

12. Gunstone, F. D.; J. Sci. Food Agric. 1999, 79, 1535. 
13. Rios, G. M.; Belleville, M. P.; Paolucci, D.; Sanchez, J.; J. Membr. Sci. 2004, 242, 189.

14. Hilal, N.; Nigmatullin, R.; Alpatova, A.; J. Membr. Sci. 2004, 238, 131.

15. Swaisgood, H. E.; Food Enzymology, Elsevier Applied Science: Essex, 1991.

16. Prazeres, D. M. F.; Cabral, J. M. S.; Enzyme Microb. Technol. 1994, 16, 738

17. Porter, M. C.; Handbook of Industrial Membrane Technology, Noyes Publications: New Jersey, 1990.

18. Pomier, E.; Galy, J.; Paolucci-Jeanjean, D.; Pina, M.; Sarrade, S.; Rios, G. M.; J. Membr. Sci. 2005, 249, 127.

19. Magnan, E.; Catarino, I.; Paolucci-Jeanjean, D.; Preziosi-Belloy, L.; Belleville, M. P.; J. Membr. Sci. 2004, 241, 161.

20. Jonsson, G.; Adler-Nissen, J.; J. Am. Oil Chem. Soc. 2000, 77, 1035.

21. Rucka, M.; Turkiewicz, B.; Enzyme Microb. Technol. 1990, 12, 52.

22. Bouwer, S. T.; Cuperus, F. P.; Derksen, J. T. P.; Enzyme Microb. Technol. 1997, 21, 291.

23. Balcão, V. M.; Malcata, F. X.; Enzyme Microb. Technol. 1998, 22, 511.

24. Lozano, P.; Pérez-Marín, A. B.; De Diego, T.; Gómez, D.; PaolucciJeanjean, D.; Belleville, M. P.; Rios, G. M.; Iborra, J. L.; J. Membr. Sci. 2002, 201, 55 .
25. Brunner, G.; J. Food Eng. 2005, 67, 21.

26. Lim, G.; Lee, S.; Lee, E.; Haam, S.; Kim, W.; Biochem. Eng. 2002, 11, 181.

27. Andersson, M. B. O.; Demirbuker, M.; Blomberg, G.; J. Chromatogr., A 1997, 785, 337

28. Castro, M. D. L.; Valcárcel, M.; Tena, M. T.; Analytical Supercritical Fluid Extraction, Springer-Verlag: Berlin, 1994.

29. Brunetti, L.; J. Am. Oil Chem. Soc. 1989, 66, 209.

30. Mendes, M. F.; Pessoa, F. L. P.; Coelho, G. V.; Uller, A. M. C.; J. Supercrit. Fluids 2005, 34, 157.

31. Mendes, R. L.; Reis, A. D.; Palavra, A. F.; Food Chem. 2006, 99, 57.

32. Gast, K.; Jungfer, M.; Saure, C.; Brunner, G.; J. Supercrit. Fluids 2005, 34, 17.

33. Cao, X.; Ito, Y.; J. Chromatogr., A. 2003, 1021, 117.

34. Sarrade, S. J.; Rios, G. M.; Carlès, M.; Sep. Purif. Technol. 1998, 14, 19.

35. Spricigo, C. B.; Bolzan, A.; Machado, R. A. F.; Carlson, L. H. C.; Petrus, J. C. C.; J. Membr. Sci. 2001, 188, 173.

36. Sarmento, L. A.; Spricigo, C. B.; Petrus, J. C. C.; Carlson, L. H. C.; Machado, R. A. F.; J. Membr. Sci. 2004, 237, 71. 